Original Article

\title{
A PILOT STUDY ON KNOWLEDGE \& PRACTICE REGARDING PREVENTION OF OCCUPATIONAL HAZARDS AND ATTITUDE TOWARDS UTILISATION OF SAFETY MEASURES AM ONG FISHERMEN WORKING AT A SELECTED HARBOR
}

\author{
Devina E. Rodrigues ${ }^{1} \&$ Udaya Kiran ${ }^{2}$ \\ ${ }^{1}$ Ph.D. Research Scholar (Nursing) Nitte University \\ ${ }^{2} U$ daya Kiran, Professor \& HOD, Community M edicine, \\ K.S. Hegde M edical Academy, Deralakatte,Nitte University M angalore -575 018, Karnataka, India \\ Correspondence \\ Devina E. Rodrigues \\ K. Pandyarajah Ballal College of Nursing, Someshwar Road, Mangalore - 575021. \\ E-mail: deves7@ rediffmail.com
}

\begin{abstract}
:
A pilot study was conducted to assess the knowledge, practice on occupational hazards and attitude towards utilization of safety measures among fishermen at $M$ alpe fishing harbor from 5-8-2012 to19-8-2012.The descriptive survey study was conducted among 40 fishermen. Convenient sampling technique was used in selection of sample. The data was collected by face to face interview using structured knowledge questionnaire with 30 items on knowledge on occupational hazards, 3 point scale to elicit the self reported practices in prevention of occupational hazards and by 5 point likert scale to determine the attitude towards utilization of safety measures. The overall knowledge indicated that $55 \%$ of the subjects had inadequate knowledge and rest had adequate knowledge related to work related hazards. In the area of psycho-social the subjects had adequate knowledge (63\%, SD 1.05); the least possession of knowledge was in the area of safety devices (47.5\%). Fishermen had moderately adequate practices (55.29\%) and area wise practice score had revealed that subjects had poor practices concerning personal protective devices. Attitude found to be moderate among fishermen (95\%).There was significant relationship between knowledge and practice score $(r=0.366, \mathrm{df}=38, \mathrm{P}=0.304)$ as well as practice and attitude scores $(r=0.370)$ at 0.05 level of significance. Found no correlation between knowledge and attitude scores. The study highlights the need to inspire the fishermen to improve their safety at work place and develop positive attitude about utilization of safety devices.
\end{abstract}

Keywords: knowledge, practice, attitude, occupational hazards, safety measures.

\section{Introduction:}

Occupational health and safety is a cross disciplinary area concerned with protecting the safety, health and welfare of the people engaged in employment ${ }^{1}$. The goal of any research in this field is to foster a safe work environment. Fishing is probably the most dangerous occupation in the world ${ }^{2}$. The people engaged in fishing are less educated.

Access this article online Quick Response Code

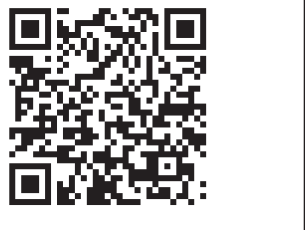

Fishermen's safety had to be addressed in a holistic way. The first and foremost step is to study and understand the situations by collecting relevant data.

Malpe fishing harbor has active commercial fishing zone having traw lers, Purseiners, motorized and non motorized boats and around 2000 fishermen actively involved in fishing operations with traditional and modern fishing techniques. The condition of work in fishing industries is arduous with high rate of accidents ${ }^{3}$. Numerous factors are known that can directly influence the health of fishermen such as physical, chemical, psycho-social and mechanical factors. In India there are no initial training sessions for fishermen. There is a need to make their life safer and comfortable for fishing. It can be done by enforcing necessary knowledge, positive attitude and safe practices at work place.

A descriptive study was conducted to determine the occupational problems among fishermen of Udupi district. 
The $77 \%$ of the fishermen had excessive exposure to sunlight, $52 \%$ were suffering from back pain and $38 \%$ had muscle cramps. All the fishermen experienced one or the other health problems related to work'. The investigator also had read several articles on local news papers regarding death, missing cases, sinking of fishing vessels, pirate attack and fire accidents at sea. This has urged the investigator to conduct a pilot study at Malpe fishing harbor.

Materials \&Methods: The study design adopted was descriptive design with survey approach. Population comprised of fishermen who are actively fishing in the sea employed or self employed at Malpe fishing harbor. Convenient sampling technique was used in selection of 40 subjects. Pretesting and reliability of the tool was ascertained before the pilot study. A written consent was obtained from the Project coordinator of fishing department and also from the subjects after explaining the purpose of the study. Each day interviewed around 3-4 fishermen using face to face interview with the help of structured knowledge questionnaire comprise of 30 items, attitude scale having 30 items and self reported practice scale with 34 items. The data was analyzed with the help of computer assisted package of social science-17 after transferring the data in to a master score sheet in M icrosoft excel. The descriptive statistics such as Frequency, \%, mean, mean \%, SD was used to describe the sociodemographic variables and overall, area wise scores related to knowledge, practice and attitude of fishermen. The relationship between the variables was elicited with the help of Karl Pearson Correlation coefficient and Annova to find out the association between research variables and socio-demographic variables.

Results: Main finding are discussed under the following headings:

\section{Overall and area wise knowledge scores on prevention of occupational hazards:}

The overall knowledge scores indicated that $55 \%$ of the subjects had inadequate knowledge and rest had adequate knowledge on work related hazards. In the area of psycho-social the subjects had adequate knowledge (63\%, SD 1.05); the least possession of knowledge was in the area of safety devices (47.5\%, SD 0.98). (Table No 1).

2. Overall and area wise practice scores on prevention of occupational hazards:

Fishermen had moderately adequate practices (55.29\%) and area wise practice score had revealed that subjects had poor practices concerning personal protective devices (Mean \% 40.13 with SD 1.99). (Table No 2).

\section{Overall and area wise attitude scores on prevention of occupational hazards:}

Overall the fishermen had moderate attitude towards utilization of safety devices. They had negative attitude in the area 'general attitude towards safety and protective devices (50.57\% and $53.71 \%$ ) respectively. They had only positive attitude towards vessel safety. (Table No.3).

\section{Significant relationship between various research variables:}

There was significant relationship between knowledge and practice score $(r=0.366, \mathrm{df}=38, P=0.304)$ as well as practice and attitude scores $(r=0.370)$ at 0.05 level of significance. The $r$ values indicates positive correlation hence, it can be described that, increase in knowledge tends to increase practices among fishermen. As well as increase in practice tends to increase attitude among fishermen. Found no correlation between knowledge and attitude scores. The study highlights the need to inspire the fishermen to improve their safety at work place and develop positive attitude about utilization of safety devices. (Table No 4 , figure $1 \& 2$ ).

\section{Significant comparison between knowledge, practice} and attitude with selected socio- demographic variables:

To compare between researches variables and sociodemographical variables one way ANOVA and t test was computed.

Found significant difference between practice and 
income of fishermen. Obtained value is $5.284, p=0.027$ and $t\left({ }_{39}\right)=2.021$ at 0.05 level of significance. Hence research hypothesis accepted on this regard.

Found significant comparison between practice scores and source of information. The obtained value is 3.373, $p$ value 0.045 . And rest of the variable had no significant comparison. (Table No 5).

\section{Discussion:}

The study conducted by Levin, et al. supports the study findings in their study around $1 / 3$ rd of fishermen expressed doubt about their knowledge of using essential safety equipments in event of emergency ${ }^{5}$.

The study conducted among Canada fishermen had specified that fishermen do not wear PFD (Personal Floatation Devices) because they have accepted the risk, they also feel PFD interferes with their movement while working on deck and there is a fear of entanglement ${ }^{6}$.

The investigation report of death of crew member of Angel fishing vessel (2003) had revealed that victim was not wearing PFD at the time of incidence though the vessel had 4 life jackets. He also had no MED (marine emergency duties) training despite of having 20 years of fishing experience?

The times of India article on 6 boats mishaps in M angalore harbor indicated that most of the boats have not installed GPS, Echo Sounder that can give personal safety for the fishermen at sea. The boat owners are reluctant to install these articles despite of having the opportunities to get subsidy on purchase of equipments ${ }^{8}$.

\section{Conclusion :}

Knowledge regarding safety devices and their practices on wearing personal protective devices are inadequate. Fishermen also do not have positive attitude towards utilization of safety devices. They need to be encouraged to purchase, wear personal safety devices. They need to be pressurized and persuade, this task can be initiated by involving local level officers, women, children and other members of the fishermen family. The present study highlights the need to conduct teaching programmes for the fishermen.

\section{Acknowledgments:}

The authors are grateful to $M$ alpe fishing harbor for giving permission to carry out this pilot project.

Figure l: Significant relationship between knowledge and practice scores:

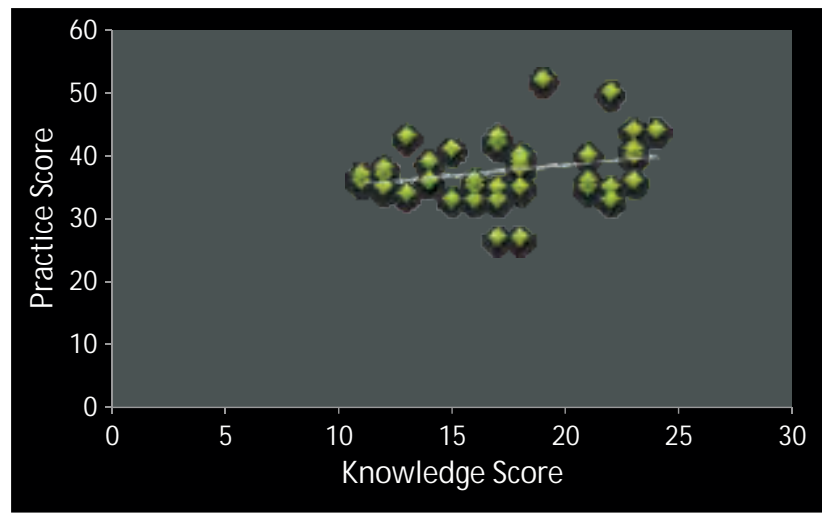

Figure 2: Significant relationship between Attitude and practice scores

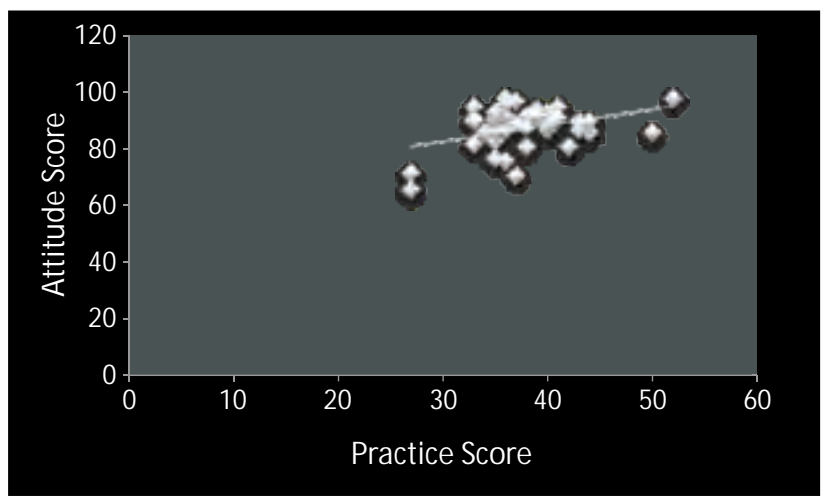

Table 1: Area wise and overall knowledge scores:

$\mathrm{n}=40$

\begin{tabular}{|l|c|c|c|}
\hline Area & M ean & SD & M ean\% \\
\hline Physical hazards & 3.60 & 1.31 & 60.00 \\
\hline Chemical hazards & 3.18 & 1.15 & 53.00 \\
\hline M uscular hazards & 5.04 & 1.53 & 60.00 \\
\hline Psycho- social hazards & 3.15 & 1.05 & 63.00 \\
\hline Safety devices & 1.90 & 0.98 & 47.50 \\
\hline Overall & 17.25 & 3.73 & 57.50 \\
\hline
\end{tabular}

Table 2: Distribution of practice scores of fishermen- area wise and overall

$n=40$

\begin{tabular}{|l|c|c|c|}
\hline Area wise & M ean & SD & M ean\% \\
\hline Before starting & 9.40 & 2.68 & 47.00 \\
\hline While working & 20.05 & 2.21 & 71.61 \\
\hline personal protective devices & 8.03 & 1.99 & 40.13 \\
\hline Overall practice & 37.60 & 4.94 & 55.29 \\
\hline
\end{tabular}


Table 3 : Overall \& Area wise distribution of attitude scores of fishermen

$n=40$

\begin{tabular}{|l|c|c|c|}
\hline Area & Mean & SD & Mean\% \\
\hline In general & 17.70 & 2.62 & 50.57 \\
\hline Wearing safety devises & 45.65 & 6.05 & 53.71 \\
\hline Vessel safety & 23.38 & 2.27 & 77.93 \\
\hline overall & 86.73 & 7.34 & 57.82 \\
\hline
\end{tabular}

Table 4: Correlation between various research variables

$$
n=40
$$

\begin{tabular}{|l|c|c|c|}
\hline Variables & $r$ & df & Table Value \\
\hline Knowledge \& Practice & $0.366^{*}$ & 38 & 0.304 \\
\hline Practice \& Attitude & $0.370^{*}$ & 38 & 0.304 \\
\hline Knowledge \& Attitude & 0.22 & 38 & 0.304 \\
\hline
\end{tabular}

Significant $=*$ : At $\varangle 0.05$ level of significance.

Table 5 : Comparison between practice and selected socio demographic variables

$n=40$

\begin{tabular}{|l|c|c|c|c|c|c|}
\hline variable & frequency & mean & SD & SE & t value & $p$ value \\
\hline Income(Rs): & & & & & & \\
Below 10,000 & 25 & 36.28 & 4.159 & 0.832 & & \\
Above 10,000 & 15 & 39.80 & 5.480 & 1.415 & 5.284 & $0.027 *$ \\
Total & 40 & 37.60 & 4.940 & 0.781 & & \\
\hline Information: & & & & & & \\
Fellow worker & 22 & 36.18 & 3.800 & 0.810 & & \\
Mass media & 10 & 40.80 & 6.746 & 2.133 & & \\
Other & 08 & 37.50 & 3.625 & 1.282 & 3.373 & $0.045^{*}$ \\
Total & 40 & 37.60 & 4.940 & 0.781 & & \\
\hline
\end{tabular}

* Significant at $<.05$ level.

\section{References:}

1. Wikipedia, encyclopedia. Occupational safety \& health (home page on the internet).US: Wikipedia foundation, Inc. c 2010-2013(updated 2013 Jan 29;cited 2013 jan31).Available from: http://en.wikipedia.org / wiki/Occupational_safety_and_health

2. Manning P.FAO Fisheries $\&$ aqua culture-safety at sea (home page on the internet). Rome: fisheries $\&$ aqua culture dept ; updated 2001 Sept 28; cited 2010 Jan 3). Available from : http://www.fao.org/fishery /topic/12272/en

3. Novalbos J, NoguerolesP, Soriguer M, Piniella F. Occupational health in Andalusia fisheries sector. Occupational medicine (Doi 10.1093/occumed /kqm156).2008 Feb 1: 58. Available from:http: //occmed.oxfordjournals.org/content/58/2/141.full.pdf thtml

4. Anusuya. Occupational health problems \& job satisfaction among fishermen. Nightingale nursing time.2010 Aug; 6(5):49-51.

5. Levin, et al. Oregon crab fishing safety assessment. Washington: Oregon health \& Science University; 2011 Dec.10p.Available from: http://depts.washington.edu/pnash/files/03_research_pub/03_ORC rab_Fishing_SafetyAsses.pdf

6. Fishing death toll remains stubbornly high, many fishermen reluctant to wear life jackets adopt safer practices.( home page on the internet).Canada: News foundland \& Labrador,inc.C CBC2013 (updated 2012 Jun 29; cited 2012 Jun 30). Available from: http://www.cbc.ca/news/canada/newfoundland-labrador/story /2012/06/29/nl-tsb-fishing-deaths-report-.html

7. Marine investigation report. Crew member lost overboard, small fishing vessel Silver Angel. Canada. Transport safety board Canada; 2011 M ay. 17 p. Report no M 11M 0017. Available from:http://www. tsb.gc.ca/eng/rapportsreports/marine/2011/m11m0017/m11m001 7.pdf

8. Six boat mishaps in 2 weeks point to apathy. The times of India.(daily edition). 23-2012 Aug: sect. times city.3p (col 1). 